\title{
CONFRONTO DE GIGANTES: OS DEBATES PRESIDENCIAIS E AS BUSCAS DOS INTERNAUTAS ESTADUNIDENSES EM 2016
}

\author{
Thiago Perez Bernardes de Moraes*
}

RESUMO: Debates eleitorais são considerados nos Estados unidos como eventos de grande impacto. Diferente de outros formatos de comunicação política, neste, os estadunidenses têm a oportunidade de conferir um "confronto direto" entre os candidatos. Neste ponto, o objetivo deste trabalho é aferir se nas eleições de 2016, os debates presidenciais influenciaram os internautas a buscarem mais informações sobre os candidatos. Trabalhamos com três hipóteses: (I) considerando a grande audiência dos debates, presumivelmente, Trump e Clinton, tiveram a visibilidade aumentada na internet por conta dos debates. (II) é crível que os debates não elevam o interesse dos internautas pelos vices. (III) visto que as pesquisas pós-debate apontaram que Clinton "venceu" os três debates, ela, mais do que Trump, pode ter sua visibilidade aumentada na internet por conta dos debates. Os resultados mostram que $1 / 4$ das buscas realizadas pelos internautas por candidatos à presidência podem ser atribuídas como consequência dos debates, o que corrobora a primeira hipótese. Aferiu-se também que não há correlação matemática entre as buscas realizadas pelos debates e a procura pelos candidatos a vice, o que confirma a segunda hipótese. Igualmente, a terceira hipótese foi conjuntamente aderente, ponderando que o efeito do debate (enquanto variável independente) foi levemente mais significante em auxiliar a ascensão das buscas dos internautas pela candidata Hillary Clinton.

PALAVRAS-CHAVE: Debates presidenciais; Eleições 2016; Donald Trump; Hillary Clinton; Internet.

\section{A MEETING OF GIANTS: PRESIDENTIAL DEBATES AND U.S. WEB BROWSERS IN 2016}

ABSTRACT: Election debates in the USA have a great impact on the population. In spite of their difference from other types of political communication, debates in the USA give the people an opportunity for a 'direct meeting' with the candidates. Current analysis verifies whether debates in the 2016 presidential election affected web browsers with regard to further information on the candidates. Three

Pós-doutorando em Direito Constitucional pelo Dipartimento di Giurisprudenza da Università Degli Studi di Messina (UNIME); Doutor em psicologia social pela Universidad Argentina John Fitzgerald Kennedy (UAJFK) e docente no Centro Universitário Campos de Andrade (UNIANDRADE), Brasil.

E-mail: thiagomoraessp@hotmail.com 
hypotheses are taken into account: (I) due to the great audience at the debates, Trump and Clinton may have had their visibility enlarged; (II) debates do not boost interest by web browsers for the candidates for vice-president; (III) since post-debate research showed that Clinton "won" the three debates, she, rather than Trump, may have had her visibility enlarged because of the debates. Results reveal that $25 \%$ of search for candidates for the presidency by web browsers may be attributed to the debates, corroborating the first hypothesis. There is no mathematical co-relationship between search due to debates and search for candidates for the vice-presidency, corroborating the second hypothesis. The third hypothesis was jointly adherent since the effect of the debate (as an independent variable) was slightly more significant to underscore search for the candidate Hilary Clinton by web browsers.

KEY WORDS: Presidential debates; 2016 elections; Donald Trump; Hillary Clinton; Internet.

\section{INTRODUÇÃO}

Nos Estados Unidos os debates eleitorais são compreendidos como elementos de "choque", sobretudo considerando que este formato se diferencia de outros tipos de mensagens políticas ao permitir um confronto entre os candidatos (algo não inteligível em outros formatos de comunicação) (ABROMOWITZ, 1978; KRAUS, 2013). Em 8 de novembro de 2016, os americanos não só escolheram o sucessor de Barack Obama (em uma das eleições mais disputadas da história americana), mas também, decidiram a composição dos votos para os 435 membros da Câmara de Representantes e 34 cargos no Senado. Entretanto, todo o "clímax" eleitoral desta eleição começou ser forjado muito antes desde as primárias (ANDRÉ, 2016). Neste diapasão o objetivo deste trabalho é estudar apenas uma das variáveis independentes que podem ter afetado a eleições de 2016: os debates presidenciais. Buscamos nessa pesquisa aferir diretamente se os debates presidenciais ocorridos nos Estados Unidos exerceram influência, no universo on-line, levando os internautas a buscarem mais informações sobre os candidatos.

Trabalhamos com três hipóteses a serem corroboradas. Primeiro, levando em conta o grande impacto que os debates presidenciais exercem no cotidiano dos estadunidenses é provável que eles, enquanto variáveis independentes afetem o interesse dos internautas pelos candidatos a presidente. No mesmo diapasão, é 
provável que os debates presidenciais não afetem de forma significativa o interesse dos internautas pelos vices. Por fim, propõe-se que, como as pesquisas realizadas após os três debates indicaram "vitória" da candidata Clinton, é provável que o "efeito" do debate eleitoral em estimular a busca do internauta tenha sido mais significativo na direção dela do que na do candidato Donald Trump. Para corroborar as hipóteses, adaptamos a metodologia proposta inicialmente por Thiago Moraes e Doacir Quadros (2016), desenvolvendo um desenho quase experimental de pesquisa por meio de dados coletados com o Google Trends acerca do interesse dos estadunidenses no período de 20/09/20016 até 07/11/2016.

\section{O TERRENO DAS ELEIÇÕES 2016}

Donald Trump e Hillary Clinton exemplificam um padrão de caricatura no que se refere à tese e à antítese do nacionalismo americano. Ambas as tradições aqui passaram por mudanças nos últimos anos em resposta a câmbios culturais e demográficos. Porém, em ambos os casos, existe a incorporação de variedade antiga da cultura americana, que remontam em alguns casos a fundação da própria república. Em termos de ideologia, as duas vertentes do nacionalismo americano se assemelham a divisões semelhantes a encontradas na Índia e na França ${ }^{2}$, ambos os países com tradição nacionalista. Podemos dizer que estas duas visões, refletem um padrão mais "expansionista" e mais defensivo (dentro da lógica que a melhor defesa é o ataque). Em termos culturais e psicológicos representam versões otimistas e pessimistas do nacionalismo americano. Estas duas faces de uma mesma moeda, os princípios dos eleitores de Trump e Clinton, são forjados em meio a uma enorme discrepância no que se referem à concentração demografia, valores culturais, posições em relação à justiça social, política externa, o papel do Estado em relação à economia, raça, inclusão e diversidade cultural (LIEVEN, 2016).

Para Anatol Lieven (2016), essa premissa está relacionada a um intenso "credo". A crença no nacionalismo cívico americano reside na fé em liberdade, no constitucionalismo, no direito, na democracia, no individualismo, no igualitarismo cultural e na política. Em algum ponto isso parece ser "resquício" de uma essência

2 Ambos os países têm uma longa tradição nacionalista, que sublinham a identidade do portador de valores universais e exigem, por conseguinte, lealdade ao "estado". Tanto na França como na Índia, esse cenário é forjado com elementos relacionados a constructos religiosos, raciais e culturais (como o sentimento de pertencimento, por exemplo) (DESAI, 2005). 
descrita já em 1830 por Alexis Tocqueville. Nas últimas décadas, a tolerância racional e a igualdade foram também amplamente concebidas enquanto um credo, e, por conseguinte, Hillary Clinton e seus partidários adicionaram a este arcabouço os direitos das mulheres e dos homossexuais.

Em relação à política externa (um dos temas pivôs da arena eleitoral) os democratas de Clinton preferem trabalhar com aliados e organizações internacionais, o que em alguma medida os faz "dispostos" a tomar medidas unilaterais quando apoiada apenas por um punhado de países europeus dependentes dos EUA. Do outro lado, a tradição ligada a Trump, que não rejeita os valores democráticos e cívicos formais do credo americano, porém, incorpora forte crença de que somente os "americanos brancos" serão capazes de "colocar a locomotiva da política nos eixos". Em parte tal tradição obviamente é profundamente militarista, entretanto, está limitada pela crença de que as guerras devem ser travadas apenas para o claro "beneficio" dos Estados Unidos (ou em resposta a ataques) (LIEVEN, 2016).

A guerra das narrativas entre Trump e Clinton relevou um contraste ideológico profundo e também diferenças de animosidades pessoais entre os dois candidatos presidenciais. Ironicamente a "doutrina Obama" continua sendo nesta eleição um fator catalisador na formação das diferenças políticas e filosóficas e também as nuanças de liderança para o futuro da América (CHERKAOUI, 2016).

Segundo Mohammed Cherkaoui (2016), a batalha eleitoral travada entre Clinton e Trump pode ser entendida como uma votação de "terceiro mandato" em favor de Barack Obama, o que é ilegal frente à Constituição dos Estados Unidos. Como Obama não pode romper com tal "obstáculo" a agenda de sua sucessora, Hillary Clinton, conta com a promessa de extensão das reformas levadas a cabo por Obama em um plano de governo composto de um híbrido entre as reformas de Obama e a concepção de política econômica de Bill Clinton. Por conseguinte, a diferença de Hillary Clinton para Donald Trump em relação às visões de mundo não se hipertrofiaram em meio a um vácuo, ao contrário, cresceram correlacionando-se com duas grandes prioridades do ano eleitoral: (I) o declínio socioeconômico da classe média; (II) o imperativo da segurança nacional frente ao pesadelo imposto pelo "Isis" em ataques contra a França.

A seguir destacamos de forma comparativa as diferenças "simbólicas" quanto

\footnotetext{
A sigla Isis é referente ao Estado Islâmico do Iraque e do Levante, também conhecido como Estado Islâmico do Iraque e da Síria. Basicamente, trata-se de uma grande organização jihadista islamita, baseados na doutrina wahhabita. O grupo é considerado como uma organização terrorista, atua principalmente no Oriente Médio e começou a galgar maior crescimento devido sua atuação na Guerra Civil Síria (MORAES; SANTOS, 2016b).
} 
à imagem políticas dos dois candidatos.

Quadro 1. Diferenças denotadas nos discursos de Trump e Clinton

\begin{tabular}{|c|c|c|}
\hline & Donald Trump & Hillary Clinton \\
\hline Slogan presidencial & $\begin{array}{l}\text { "Make American Great Again." } \\
\text { "American First." }\end{array}$ & $\begin{array}{l}\text { "Hillary for America." "Stronger } \\
\text { Together.' "Breaking down } \\
\text { barriers." "Fighting for us." "I'm } \\
\text { with her." }\end{array}$ \\
\hline $\begin{array}{l}\text { Nós centrais de } \\
\text { identificação / } \\
\text { identidade }\end{array}$ & $\begin{array}{l}\text { Classe média branca anglo- } \\
\text { saxônica protestante (WASP) }\end{array}$ & $\begin{array}{l}\text { Americanos de diferentes étnicas, } \\
\text { origens e religiões. }\end{array}$ \\
\hline Filosofia política & $\begin{array}{l}\text { Entre o realismo político e a } \\
\text { doutrina comercial. }\end{array}$ & $\begin{array}{l}\text { Pragmatismos político e um } \\
\text { compromisso com a diplomacia } \\
\text { mundial. }\end{array}$ \\
\hline $\begin{array}{l}\text { Relação entre os } \\
\text { Estados Unidos e o } \\
\text { resto do mundo }\end{array}$ & $\begin{array}{l}\text { Falta de inovação política e } \\
\text { consequentemente declínio } \\
\text { econômico. }\end{array}$ & $\begin{array}{l}\text { Grande e de crescente } \\
\text { importância. }\end{array}$ \\
\hline $\begin{array}{l}\text { Visão sobre a atual } \\
\text { situação dos Estados } \\
\text { Unidos e suas relações } \\
\text { internacionais }\end{array}$ & $\begin{array}{l}\text { Catastrófica e carece de } \\
\text { negociadores experientes. }\end{array}$ & $\begin{array}{l}\text { Demanda mais medidas para a } \\
\text { proteção da segurança nacional. }\end{array}$ \\
\hline Uso da força & $\begin{array}{l}\text { Desenvolvimento de força militar } \\
\text { conjunto ao rompimento de } \\
\text { uma forte tradição relacionada à } \\
\text { política externa. }\end{array}$ & $\begin{array}{l}\text { Uma abordagem " } 3 \mathrm{~d} \text { " para lidar } \\
\text { com o problema da dependência } \\
\text { energética de forma inteligente: } \\
\text { diplomacia, desenvolvimento e } \\
\text { defesa. }\end{array}$ \\
\hline $\begin{array}{l}\text { Nova aproximação com } \\
\text { Cuba }\end{array}$ & $\begin{array}{l}\text { Não trouxe respeito algum para } \\
\text { Barack Obama. }\end{array}$ & $\begin{array}{l}\text { A presença dos Estados Unidos } \\
\text { em Cuba é necessária. }\end{array}$ \\
\hline Conceito de câmbio & $\begin{array}{l}\text { A liderança política deve } \\
\text { corresponder a uma "gestão de } \\
\text { negócios" }\end{array}$ & Demanda reformas incrementais. \\
\hline $\begin{array}{l}\text { Relação entre Obama e } \\
\text { a assinatura da reforma } \\
\text { legislativa }\end{array}$ & $\begin{array}{l}\text { Deve ser revogado e substituído } \\
\text { por algo melhor. }\end{array}$ & $\begin{array}{l}\text { Representa uma grande conquista, } \\
\text { sobretudo no que também as } \\
\text { falhas do sistema de saúde da } \\
\text { década de } 1990 \text {. }\end{array}$ \\
\hline
\end{tabular}

Fonte: adaptado a partir de Mohammed Cherkaoui (2016). 
De toda forma, podemos considerar que talvez Donald Trump, e seu êxito eleitoral, seja antes de tudo um epifenômeno da ascensão de uma tendência "autoritária" no arcabouço ideológico dos estadunidenses (ANDRÉ, 2016).

Mas ainda assim contra essa premissa, Robert Mather e Kurt Jefferson (2016) afirmam que por mais que seja interessante estabelecer uma relação empírica entre a ascensão de Trump e a permanência de valores autoritários, isso pode contar apenas parte da história das eleições de 2016, mas não ela inteira. Isso lucubrando que alguns elementos do realinhamento partidário podem prever o desenvolvimento de uma fluidez de valores e visões dentro de orientação de classe. É dizer que os eleitores "autoritários" podem ser encontrados em diferentes grupos de votos políticos e, embora o velho tipo "Tea Party" e independentes podem se inclinar a votar em Trump, é inteiramente possível que exista um perfil autoritário de eleitor de esquerda, como o eleitor de classe média mais jovem que representou uma consistente base de apoio de Bernie Sanders. Mais ainda assim é possível sugerir que a candidatura de Trump seja um produto do apelo à identidade branca, que está sob "ameaça", visto que, as políticas conservadoras enfatizam a manutenção da hierarquia social (MATHER; JEFFERSON, 2016).

\section{DEBATES PRESIDENCIAIS E ELEIÇÕES 2016}

Eduardo Cintra Torres (2005, 2016) alvitra seis lições importantes relacionadas aos estudos dos debates televisionados de candidatos à presidência: (I) a avaliação do efeito dos debates é ad hoc permeada em complexidade, isso considerando que tende a se confundir com a avaliação dos efeitos dos meios de comunicação, o que por sua vez gerou uma série de teorias contraditórias entre si; (II) os debates não emergem em uma existência isolada, ao contrário, englobam-se em um contínuo fluxo de informações e comentários mediáticos que se permeiam por toda agenda. Empiricamente, os debates são mais relevantes que outros eventos da campanha eleitoral, são o "ponto alto"; (III) além disso, existe também o fluxo de informação pós-debate, onde o conteúdo do debate vira o recheio da agenda mediática, dando lastro ao discurso dos comentaristas, ao enquadramento dos jornais etc.; (IV) existe também um relevante impacto indireto resultante da posterior troca social com familiares, amigos e colegas, onde o tema debate presidencial vira parte do "eixo de discussão" do dia a dia; (V) indubitavelmente existe também o impacto das crenças e preferências prévias dos indivíduos que explicam a audiência de um 
debate e sua polarização em relação aos candidatos (e eleitores), mesmo antes da participação dos mesmos; (VI) significante nesta seara também está a questão do "desempenho" do candidato, onde os eleitores podem estar cognitivamente mais motivados a "premiar" aqueles que tiveram o "melhor resultado" (mesmo que isso às vezes implique em mudar de opinião).

Nos Estados Unidos a literatura aponta que o debate presidencial é mais do que uma parte do processo institucionalizada ou uma comunicação política, é como um "ritual sagrado", um momento aguardado e celebrado com expectativa por uma parcela enorme do eleitorado americano. A principal razão da ansiedade dos eleitores em relação aos debates é que nesta arena os candidatos são confrontados com um potencial de "refutação iminente" algo não aferível em nenhum outro momento específico da campanha eleitoral (ABRAMOWITZ, 1978; KRAUS, 2013).

Em 2016 foram realizados três debates presidenciais. No gráfico, a seguir, destacamos o posicionamento segundo as agências sobre o "desempenho" dos candidatos e a média geral.

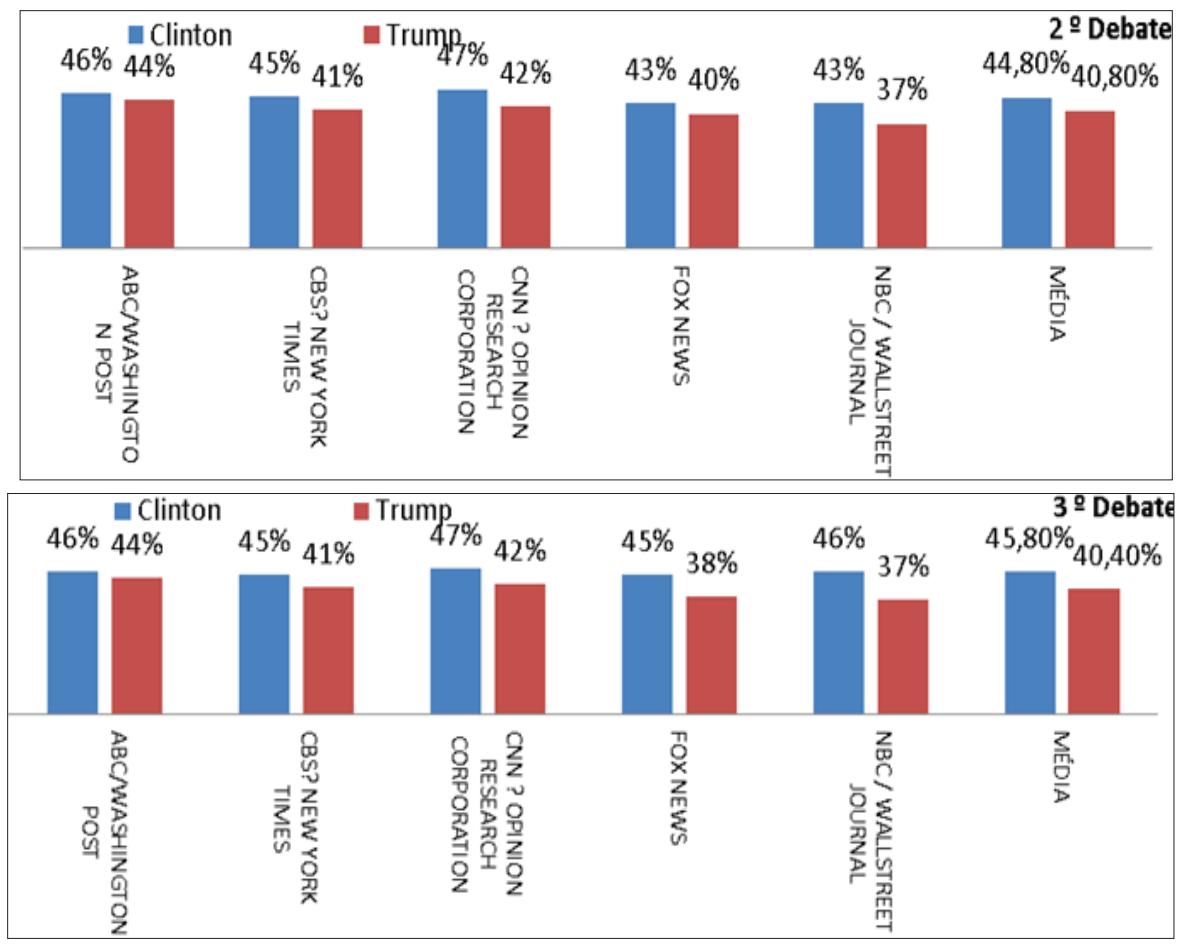

Gráfico 1. Pesquisas pós-debates

Fonte: adaptado á partir de WINNEG; JAMIESON, 2017. 
Após o primeiro debate a maioria das pesquisas de opinião apontava Hillary Clinton como predileta com uma média de 43\% contra 40\% de seu adversário Donald Trump. O segundo debate tem na visão de carta de "campo de batalha". Manteve-se após o segundo debate, nas pesquisas de opinião, as mesmas tendências observadas em resposta ao primeiro debate. Nesse ponto, Hillary Clinton pontuou em uma média de 44,80\% contra 40,80 de seu adversário.

A pesquisa realizada após o terceiro debate não só marca a continuidade de uma mesma tendência (em comparação com as pesquisas anteriores), mas, além disso, lobriga que Hillary Clinton obteve ainda mais "apoio" neste momento que em outros. Aqui ela pontuou como uma média de 45,80\% contra 40,40\% de Donald Trump.

\section{ELEIÇÕES 2016 E INTERNET}

Os pesquisadores da Universidade de Rochester Yu Wang, Yuncheng Li e Jiebo Luo (2016) estudaram a demografia dos seguidores de Donald Trump e Hillary Clinton no Twitter ${ }^{4}$, em um banco de dados construído de setembro de 2015 até dezembro de 2015. Descobriu-se a princípio que os apoiadores de Trump são mais polarizados que os da Clinton: isso considerando que eles tendem a ter tanto larga influência como também pouca ou nenhuma. Além disso, em comparação aos seguidores da Clinton, os de Trump são mais propensos a serem, ou muito mais velhos ou muito mais jovens. Em outras palavras, os apoiadores de Trump representam um perfil muito mais heterogêneo. Todavia, foi possível aferir também que os seguidores da Clinton foram mais racialmente diversificados.

Ainda no universo do Twitter, Walid Magdy e Kareem Darwish (2016), realizou-se uma análise quantitativa e qualitativa referente ao potencial de "viralidade" dos principais tweets relacionados ao candidato Donald Trump e para a candidata Hillary Clinton. A análise compreendeu o período de setembro até

\footnotetext{
O Twitter é uma rede social baseada em publicações com no máximo 140 caracteres de extensão. Foi lançado em 206 e rapidamente se tornou uma das mais populares mídias sociais. O Twitter produz conteúdo que alimenta outras redes sociais, e é utilizado hoje para fins diversos, como atualização de status, conversa com outros internautas, compartilhamento de opiniões de terceiros, promoções de spams, dentre outros (MORAES; SANTOS, 2016a).
} 
outubro de 2006, e denotou que os tweets que eram favoráveis a Donald Trump tinham maior probabilidade de serem compartilhados que os tweets que favoreciam a imagem de Hillary Clinton. A única exceção foi o primeiro debate presidencial e também após o lançamento da fita "Acces Hollywood". Outro ponto interessante é que aparentemente neste estudo os três debates presidenciais causaram aumento no padrão de interação no Twitter em relação aos dois candidatos.

Kevin Reuning e Nicholas Dietrich (2016), ambos da Pennsylvania State University, desenvolveram um quase experimento para medir e comparar o papel das mídias nas eleições primárias de 2012 e 2016. Os autores utilizaram modelos de séries temporais que levaram em conta processos endógenos e dados de mídias originais coletados da cobertura televisiva. Os resultados mostram que as mudanças na cobertura da mídia são consistentemente significativas para explicar, enquanto variável independente, o apoio e o interesse público durante as eleições primárias. Existem também evidências de uma relação endógena pelo qual a mídia responde a alterações no interesse público. Nesta pesquisa o fator "pesquisa de opinião" teve pouco poder explicativo sobre a alteração de apoio aos candidatos a presidente.

Jayeon Lee e Young-Shin Lim (2016) pesquisaram o padrão de comportamento dos candidatos Donald Trump e Hillary Clinton em seus sites pessoais e suas contas de Twitter. Os resultados apontaram um padrão de discrepância consistente no que se refere à ênfase pessoal, a questões veiculadas, no conteúdo principal dos tweets, nas fontes de retweet, no uso de multimídia e no nível de civilidade. Dentro desta seara, Trump utilizou mais conteúdo de tweets gerados por outros usuários enquanto, nesse ponto, $3 / 4$ dos tweets de Clinton são de conteúdo original enquanto metade dos tweets de Trump são compartilhamentos de respostas aos cidadãos. $\mathrm{O}$ conteúdo mais popular fora a opinião de Clinton sobre políticas públicas e endossos dos outros ou citações de apoio a Donald Trump. 1/10 dos tweets de Trump possuem alguma menção de baixa "civilidade". Além disso, Clinton fez amplo uso da multimídia diversificada, com recursos como gráficos, vídeos, fotos, links enquanto 79,3\% dos tweets de Trump eram basicamente de textos.

Outro assunto recente na literatura da comunicação política é a participação

5 Durante as eleições presidenciais de 2016, o jornal Washington Post lançou um vídeo e um artigo com imagens onde supostamente Donald Trump e Billy Bush trocam uma conversa muito lasciva sobre um encontro com mulheres em 2005. Esse "evento" foi apelidado por alguns jornalistas e outros influenciadores de opinião como o Pussygate (ELRICK, 2016). 
de "bots", na propagação de informação política. Bots são definidos como contas de mídias sociais que interagem automaticamente com outros usuários, exercendo possivelmente um papel singular dentro de crises políticas e períodos eleitorais. Neste ponto, Bence Kollanyi, Philip Howard e Samuel Woolley (2016) buscaram aferir se o uso de bots fora significativo dentro das eleições de 2016. Os resultados aferiram que primeiramente, encontrou-se o dobro de hashtags pró-Trump em comparação com hashtags pró-Clinton. Além disso, aferiu-se que cerca de $1 / 3$ da participação pró-Trump foi veiculada via bots, enquanto no que se refere às hashtags pró-Clinton, a margem de bots é em torno de 1/5 das contas. Apesar da influência dos bots, os picos generalizados no aumento da veiculação das hashtags estão associados à participação e interação de usuários reais.

\section{METODOLOGIA}

Neste estudo traçamos um quase experimento natural para aferir em que medida o debate presidencial norte-americano pode afetar a agenda do interesse dos internautas em relação aos candidatos à presidência e seus respectivos vices.

Como bem ensina George Eliopoulos e seus colaboradores (2004), quase experimentos são estudos que visam avaliar intervenções, mas que não utilizam métodos de aleatorização. Tal como em ensaios randomizados, as quase-experiências visam demonstrar a causalidade entre uma ou mais variáveis independentes e uma variável dependente. Todavia, nesse caso, a variável independente não é trazida à cena induzida artificialmente pelo pesquisador, mas observa-se post factum como as variáveis se relacionaram naturalmente. Paolo Parigi, Jessica Santana e Karen Cook (2017) lobrigam que este tipo de metodologia, quando utiliza como fonte a "big Data da internet", oferece vias consistentes para captar condições ambientais teoricamente relevantes e ao mesmo tempo é possível maximizar o controle do pesquisador. Por conta disso, este tipo de metodologia é de especial utilidade para cientistas sociais por causa de seu foco nas interações sociais e nos fatores que influenciam a natureza e a estrutura das interações.

Aqui replicamos a metodologia proposta por Thiago Moraes e Doacir 
Quadros (2016) sugerida para estudar o efeito dos debates eleitorais no Brasil. Basicamente esta metodologia demanda três passos:

I.) esquadrinhar com o Google Trends uma frequência temporal relativa às buscas executadas no Google pelo tema debate presidencial, durante o período eleitoral. Esta será a variável independente do modelo;

II.) definir frequências temporais relativas às buscas efetuadas no Google pelos candidatáveis que participaram dos debates. Tais variáveis são tidas aqui como dependentes;

III.)por fim, construir um modelo de regressão linear para testar o efeito que a distribuição temporal das buscas no Google pelos debates teve em relação às buscas pelos dos internautas pelos candidatos à presidência.

Em nosso estudo, coletamos com o Google Trends (bttps://trends.google. com) dados sobre as buscas registradas no Google pelos candidatos Donald Trump e Hillary Clinton, pelos vices Tim Kaine e Mike Pence e também as buscas efetuadas por debates. Assim como recomendado em Moraes e Quadros (2016), elencamos apenas frequências de dados do tipo "beta".

O Google Trends é como um motor de busca reversa ${ }^{7}$, oferecendo para cada termo ou tópico buscado a distribuição temporal e ou espacial com que o tópico foi buscado pelos usuários do Google. Em todos os casos ele gera uma escala de 0 (baixíssima frequência de buscas) a 100 (altíssima frequência de buscas) (PREIS; MOAT, 2014; MORAES; SANTOS, 2013, 2015). Como recorte temporal considerou-

6 A frequência Beta considera não só um termo, mas um tópico, levando em conta diversas formas de grafia e idiomas diferentes. Isso é possível, pois a ferramenta traça correlação frente não só a uma busca de um usuário, mas um conjunto de buscas diárias. Por conta disso, este tipo de frequência, temporal ou espacial, quando segmentada por tópico, representa um "retrato" muito mais preciso da "realidade" (SONG et al., 2014; MORAES et al., 2014; MORAES, 2016).

7 Enquanto um motor de busca tradicional como o Google oferece uma lista de hyperlinks relacionados a determinado termo buscado, o Google Trends e outros motores de busca reversa como o Baidu Index realizam o processo contrário. Ou seja, para cada termo ou tópico buscado, a ferramenta gera dados relativos à distribuição temporal e espacial de buscas efetuadas em praticamente todos os países e em qualquer período do tempo desde janeiro de 2004. As distribuições espaciais e temporais são normalizadas dentro de uma métrica que vai de 0 a 100 . Vale destacar que todos os dados estão disponíveis gratuitamente para download. Considerando que o Google é o motor de busca mais usado no mundo (com mais de 7 bilhões de buscas efetuadas por dia) o conteúdo do Google Trends não é só de grande valor para as ciências sociais, mas para além disso, representa o maior banco de dados sobre "preferências" humanas (PREIS; MOAT, 2013; SONG et al., 2014). 
se o período de 20/09/20016 até 07/11/2016 e como recorte espacial considerou-se unicamente os Estados Unidos. Para todos os casos estatísticos utilizamos o intervalo de confiança de $95 \%$.

\section{RESULTADOS}

No Quadro 2 plotamos as estatísticas descritivas relativas às buscas dos usuários de internet nos Estados Unidos durante o período contemplado em nossa análise.

Quadro 2. Estatísticas

\begin{tabular}{|c|c|c|c|c|c|c|}
\hline & & Donald_Trump & Hillary_Clinton & Debate & Tim_Kaine & Mike_Pence \\
\hline & Válido & 50 & 50 & 50 & 50 & 50 \\
\hline $1 \sqrt{ }$ & Ausente & 0 & 0 & 0 & 0 & 0 \\
\hline & & 30,12 & 16,44 & 9,20 & ,18 & , 40 \\
\hline $\mathrm{Mc}$ & & $13^{\mathrm{a}}$ & 13 & 1 & 0 & 0 \\
\hline & padrão & 16,130 & 9,362 & 18,586 & ,873 & 1,050 \\
\hline & & 64 & 45 & 99 & 6 & 6 \\
\hline & & 12 & 8 & 1 & 0 & 0 \\
\hline & & 76 & 53 & 100 & 6 & 6 \\
\hline So & & 1506 & 822 & 460 & 9 & 20 \\
\hline
\end{tabular}

Fonte: Dados da pesquisa.

Verifica-se que Donald Trump fora praticamente duas vezes mais buscado nos motores de busca do Google em comparação com a candidata Hillary Clinton. Os resultados indicam que, apesar dos debates possivelmente terem algum efeito, o protagonista nas buscas dos internautas norte-americanos é primeiramente o tema "candidatos", e em medida muito menor, os debates.

Apesar disso, como bem expresso no gráfico e também na descrição da 
amplitude, os debates eleitorais conseguem ganhar um espaço considerável dentro do universo de buscas dos internautas. No dia do primeiro confronto televisivo entre os presidenciáveis as buscas por debate superaram o volume de entradas no Google relativas aos candidatos. Nos demais debates, estas faixas foram equivalentes. A busca pelos vices mostrou um padrão muito baixo, ou seja, em vista dos candidatos, os vices despertaram um volume de buscas ínfimo entre os internautas. Exibimos Gráfico 2 a distribuição temporal das frequências de interesse registradas no Google.

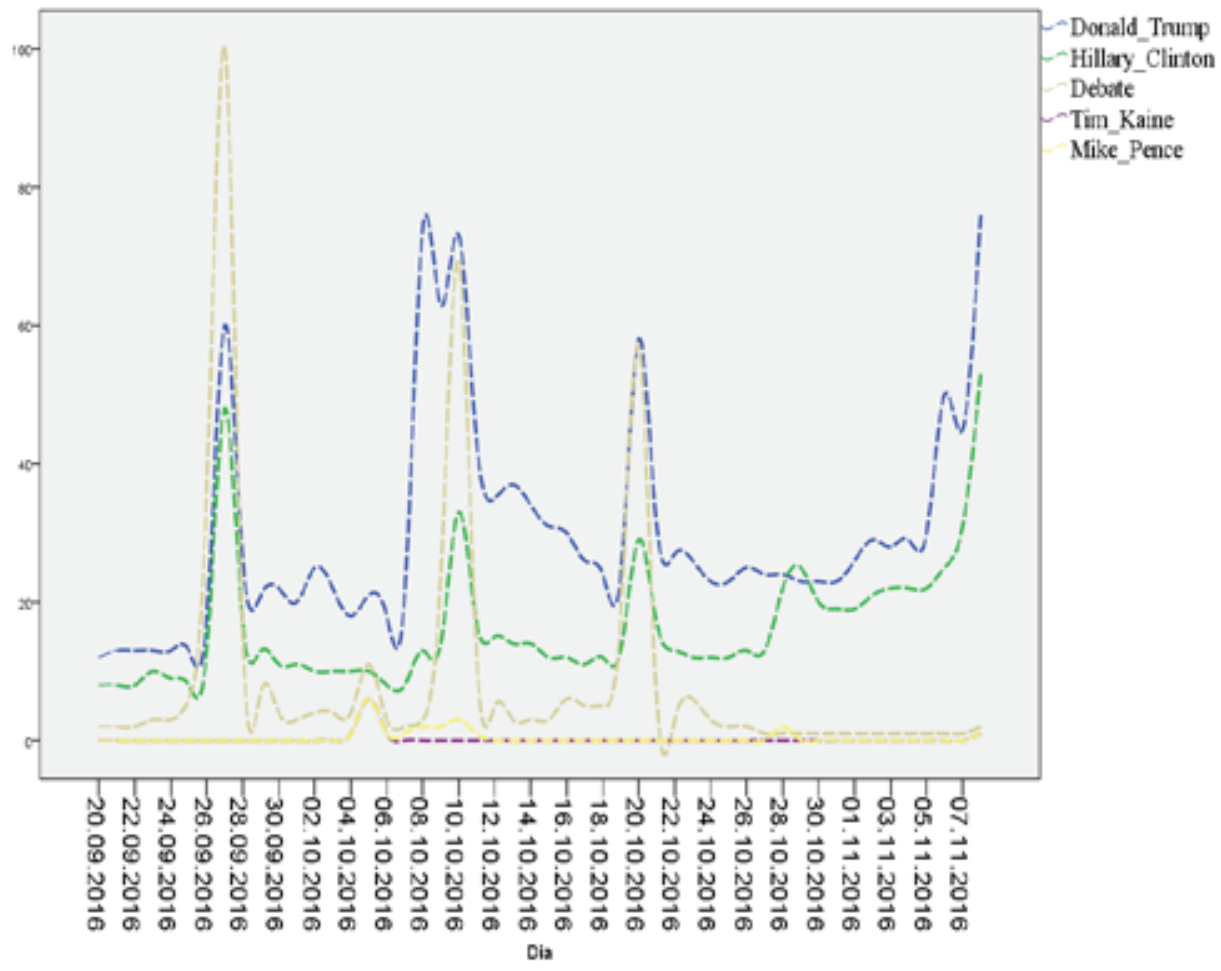

Gráfico 2. Distribuição temporal de interesse Fonte: o autor á partir do Google Trends.

O valor de buscas pelo candidato Donald Trump varia de 12 (20 de setembro) a 76 (08 de novembro de 2016), com a maior parte dos valores sendo os mais baixos. A mediana é 25. Os valores exceção para Donald Trump em: 60 (27 de setembro de 2016), 74 (8 de outubro), 73 (10 de outubro) e 58 (20 de outubro).

Já a frequência de buscas pela candidata Hillary Clinton varia de 8 (20 de 
setembro de 2016, 21, 22) a 53 (8 de novembro de 2016) em que $80 \%$ dos valores é menor ou igual a 22. Os valores principais de exceção para Hillary Clinton: em 48 (27 de setembro), 33 (10 de outubro), 29 (20 de outubro) e 53 (8 de novembro). É interessante notar que o interesse por debate segue uma rota decrescente, ou seja, o primeiro debate causa grande pico, mas em relação ao segundo e terceiro, as buscas declinam. Traçamos a seguir correlações utilizando o índice de Pearson considerando as buscas dos internautas estadunidenses medidas por debates, os valores relativos aos candidatos a presidente e seus respectivos vices.

Tabela 3. Correlações

\begin{tabular}{|c|c|c|c|c|c|c|}
\hline & & $\begin{array}{c}\text { Donald_ } \\
\text { Trump }\end{array}$ & $\begin{array}{l}\text { Hillary_- } \\
\text { Clinton }\end{array}$ & Debate & $\begin{array}{l}\text { Tim } \\
\text { Kaine }\end{array}$ & $\begin{array}{l}\text { Mike } \\
\text { Pence }\end{array}$ \\
\hline \multirow{3}{*}{$\begin{array}{l}\text { Donald } \\
\text { Trump }\end{array}$} & $\begin{array}{l}\text { Correlação de } \\
\text { Pearson }\end{array}$ & 1 &, $707^{* *}$ & , $499^{* *}$ &,- 048 &, $290^{*}$ \\
\hline & $\begin{array}{l}\text { Sig. ( } 2 \\
\text { extremidades) }\end{array}$ & & , 000 & ,000 &, 741 & ,041 \\
\hline & $\mathrm{N}$ & 50 & 50 & 50 & 50 & 50 \\
\hline \multirow{3}{*}{$\begin{array}{l}\text { Hillary } \\
\text { Clinton }\end{array}$} & $\begin{array}{l}\text { Correlação de } \\
\text { Pearson }\end{array}$ &, $707^{* *}$ & 1 &, $509^{* *}$ &,- 042 &, 050 \\
\hline & $\begin{array}{l}\text { Sig. ( } 2 \\
\text { extremidades) }\end{array}$ & ,000 & & ,000 & ,770 & ,729 \\
\hline & $\mathrm{N}$ & 50 & 50 & 50 & 50 & 50 \\
\hline \multirow{3}{*}{ Debate } & $\begin{array}{l}\text { Correlação de } \\
\text { Pearson }\end{array}$ &, $499^{* *}$ &, $509^{* *}$ & 1 &,- 010 & , 176 \\
\hline & $\begin{array}{l}\text { Sig. }(2 \\
\text { extremidades) }\end{array}$ & ,000 &, 000 & & ,946 & ,222 \\
\hline & $\mathrm{N}$ & 50 & 50 & 50 & 50 & 50 \\
\hline \multirow{3}{*}{ Tim_Kaine } & $\begin{array}{l}\text { Correlação de } \\
\text { Pearson }\end{array}$ &,- 048 &,- 042 &,- 010 & 1 &, $788^{* *}$ \\
\hline & $\begin{array}{l}\text { Sig. }(2 \\
\text { extremidades) }\end{array}$ &, 741 & ,770 & ,946 & & ,000 \\
\hline & $\mathrm{N}$ & 50 & 50 & 50 & 50 & 50 \\
\hline \multirow{3}{*}{$\begin{array}{l}\text { M i k e } \\
\text { Pence }\end{array}$} & $\begin{array}{l}\text { Correlação de } \\
\text { Pearson }\end{array}$ & ,290* &, 050 & ,176 &, $788^{* *}$ & 1 \\
\hline & $\begin{array}{l}\text { Sig. }(2 \\
\text { extremidades) }\end{array}$ & ,041 &, 729 & ,222 & ,000 & \\
\hline & $\mathrm{N}$ & 50 & 50 & 50 & 50 & 50 \\
\hline
\end{tabular}

**. A correlação é significativa no nível 0,01 (2 extremidades).

*. A correlação é significativa no nível 0,05 (2 extremidades).

Fonte: Dados da pesquisa. 
É interessante observar que não existe correlação entre os debates e as buscas no Google pelos vices Tim Kaine e Mike Pence, o que nos leva a concluir que, os debates presidenciais não elevam o interesse dos internautas pelos candidatos à vice. Porém, existe significativa relação positiva entre os debates e os candidatos Donald Trump e Hillary Clinton.

A seguir para melhor entender esta relação, gizamos duas regressões lineares em que o interesse por debate se caracteriza como variável independente e o interesse dos internautas pelos candidatos Trump e Clinton são variáveis dependentes.

Tabela 4. Regressão linear

(continuna)

Regressão linear Donald Trump e Debate

\begin{tabular}{|c|c|c|c|c|c|c|}
\hline \multicolumn{2}{|c|}{ Modelo } & $\mathbf{R}$ & R quadrado & $\begin{array}{l}\text { R quadrado } \\
\text { ajustado }\end{array}$ & \multicolumn{2}{|c|}{$\begin{array}{l}\text { Erro-padrão da } \\
\text { estimativa }\end{array}$} \\
\hline \multicolumn{2}{|l|}{1} &, $499^{\mathrm{a}}$ & ,249 & ,233 & \multicolumn{2}{|c|}{14,126} \\
\hline \multicolumn{2}{|c|}{ Modelo } & $\begin{array}{l}\text { Soma dos } \\
\text { quadrados }\end{array}$ & df & Quadrado médio & $\mathbf{F}$ & Sig. \\
\hline \multirow{3}{*}{1} & Regressão & 3171,570 & 1 & 3171,570 & 15,895 &, $000^{\mathrm{b}}$ \\
\hline & Resíduos & 9577,710 & 48 & 199,536 & & \\
\hline & Total & 12749,280 & 49 & & & \\
\hline \multirow{2}{*}{\multicolumn{2}{|c|}{ Modelo }} & \multicolumn{2}{|c|}{ Coeficientes não padronizados } & $\begin{array}{l}\text { Coeficientes } \\
\text { padronizados }\end{array}$ & \multirow{2}{*}{$\mathbf{t}$} & \multirow{2}{*}{ Sig. } \\
\hline & & B & $\begin{array}{l}\text { Modelo } \\
\text { padrão }\end{array}$ & Beta & & \\
\hline \multirow[b]{2}{*}{1} & (Constante) & 26,138 & 2,233 & & 11,703 &, 000 \\
\hline & Debate & ,433 & ,109 & ,499 & 3,987 &, 000 \\
\hline
\end{tabular}


(Conclusão)

\begin{tabular}{|c|c|c|c|c|c|c|}
\hline \multicolumn{7}{|c|}{ Regressão linear Hillary Clinton e Debate } \\
\hline \multicolumn{2}{|c|}{ Modelo } & $\mathbf{R}$ & $\begin{array}{c}\text { R } \\
\text { quadrado }\end{array}$ & $\begin{array}{l}\text { R quadrado } \\
\text { ajustado }\end{array}$ & \multicolumn{2}{|c|}{$\begin{array}{c}\text { Erro-padrão da } \\
\text { estimativa }\end{array}$} \\
\hline \multicolumn{2}{|l|}{1} &, $509^{\mathrm{a}}$ & ,259 & ,244 & \multicolumn{2}{|c|}{8,140} \\
\hline \multicolumn{2}{|c|}{ Modelo } & $\begin{array}{c}\text { Soma dos } \\
\text { quadrados }\end{array}$ & df & $\begin{array}{l}\text { Quadrado } \\
\text { médio }\end{array}$ & $\mathbf{F}$ & Sig. \\
\hline \multirow{3}{*}{1} & Regressão & 1114,154 & 1 & 1114,154 & 16,817 &, $000^{c}$ \\
\hline & Resíduos & 3180,166 & 48 & 66,253 & & \\
\hline & Total & 4294,320 & 49 & & & \\
\hline \multirow{2}{*}{\multicolumn{2}{|c|}{ Modelo }} & \multicolumn{2}{|c|}{$\begin{array}{c}\text { Coeficientes não } \\
\text { padronizados }\end{array}$} & $\begin{array}{l}\text { Coeficientes } \\
\text { padronizados }\end{array}$ & \multirow{2}{*}{$\mathbf{t}$} & \multirow{2}{*}{ Sig. } \\
\hline & & B & $\begin{array}{l}\text { Modelo } \\
\text { padrão }\end{array}$ & Beta & & \\
\hline \multirow[b]{2}{*}{1} & (Constante) & 14,080 & 1,287 & & 10,940 &, 000 \\
\hline & Debate & ,257 &, 063 & ,509 & 4,101 &, 000 \\
\hline
\end{tabular}
a. Preditores: (Constante), Debate.
b. Variável dependente: Donald_Trump.
c. Variável dependente: Hillary__Clinton
Fonte: Dados da pesquisa.

Em ambos os casos, a variável independente exerceu pressão significativa corroborada pelo coeficiente de ANOVA e pelos valores do teste de $t$-student. Os valores de $r$ quadrado ajustado mostram que a variável independente foi responsável por $24,9 \%$ das buscas dos internautas por Donald Trump e por $25,9 \%$ das buscas pela candidata Hillary Clinton no Google. Isso indica que para ambos, o debate eleitoral representou um trampolim para atingir a agenda de buscas dos internautas, porém, o efeito 2 levemente mais significativo em relação a Clinton. Apesar disso, as buscas por Donald Trump foram mais frequentes em praticamente todo período mensurado. 
O fato de o efeito debate eleitoral ser levemente mais significativo para a candidata Hillary Clinton do que para o Candidato Donald Trump pode ter relação, como já elencado, com a maior parte das pesquisas de opinião pós-debate que declaravam que, na opinião do "público", Clinton seguia na "dianteira" (WINNEG; JAMIESON, 2017). O fato é que, tanto para um candidato, como para outro, o efeito debate eleitoral, no universo dos internautas estadunidenses, pode explicar enquanto variável independente $1 / 4$ das buscas registradas pelos candidatos. Isso não só indica que o debate tem efeito significativo em alterar a agenda do interesse dos internautas, mas, além disso, sugere que os debates podem ser elementos pivôs dentro das corridas presidenciais norte-americanas.

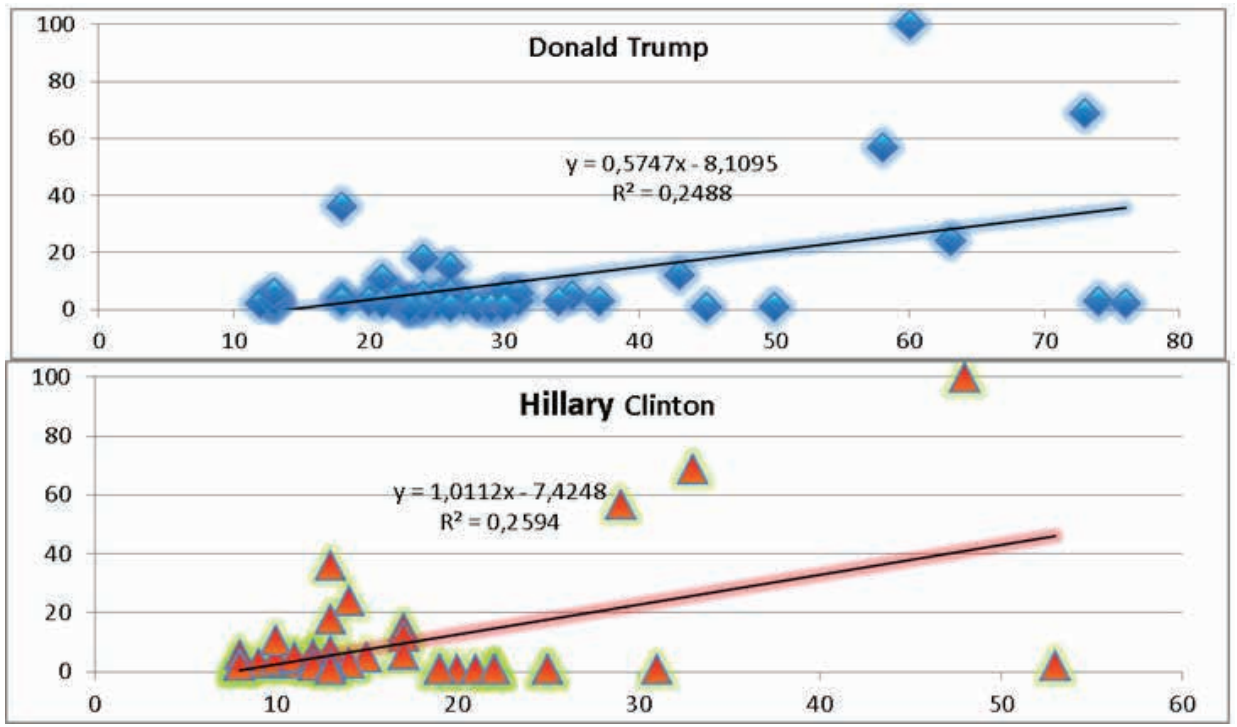

Gráfico 3. Dispersão entre as buscas por debate e pelos candidatos Trump e Clinton Fonte: o autor.

\section{CONSIDERAÇÕES FINAIS}

A primeira hipótese foi corroborada com larga aderência, ou seja, o efeito debate eleitoral funcionou como uma mola propulsora, elevando entre os internautas tanto as buscas em relação à candidata Clinton, como em relação ao 
candidato Donald Trump. Este foi um efeito muito parecido com o encontrado outrora por Thiago Moraes e Doacir Quadros (2016), quando se estudou o efeito do debate presidencial nas buscas dos internautas brasileiros. Isso denota que a "agenda" do universo on-line não se desenvolve de forma aleatória e ou livre de outros efeitos, ao contrário, ela se desenvolve em consonância com acontecimentos da esfera off-line.

O efeito causado pelo debate eleitoral (de elevar as buscas realizadas pelos internautas) foi levemente mais forte em relação à candidata Hillary, o que corrobora nossa terceira hipótese. Mas mesmo com tal efeito, a frequência de buscas dos internautas pelo candidato Donald Trump permaneceu maior durante todo o período analisado. De todo modo, os resultados confirmam a premissa de que os debates são importantes para as eleições americanas (ABRAMOWITZ, 1978; ANDRÉ, 2016), visto que praticamente $1 / 4$ das buscas dos internautas pelos candidatos pode ser explicado pelo fator debate presidencial. A segunda hipótese também se corrobora, vide que, não houve correlação tangível entre as buscas dos internautas por debates e pelos respectivos vices. Como recomendação, propõe-se que em estudos futuros a metodologia proposta por Thiago Moraes e Doacir Quadros (2016) seja replicada em outras democracias do mundo que prevêem o uso do debate presidencial televisivo em períodos eleitorais.

\section{REFERÊNCIAS}

ABRAMOWITZ, A. I. The impact of a presidential debate on voter rationality. American Journal of Political Science, p. 680-690, 1978. Disponível em: < http:// www.jstor.org/stable/2110467 > Acesso em: 13 out. 2016.

ANDRÉ, J. G. 2016: A longa caminhada: das eleições primárias à sucessão de Obama. Relações Internacionais (R: I), n. 51, p. 27-41, 2016. Disponível em: $<$ http://www.scielo.mec.pt/pdf/ri/n51/n51a03.pdf > Acesso em: 12 Dez. 2016.

CHERKAOUI, M. Clinton versus Trump: Two-Distant Visions for America. Al Jazeera Centre For Studies, p.17, 2016. Disponível em: < http://studies.aljazeera.net/ 
mritems/Documents/2016/8/23/67a0ed56cc4c4ed187c23ae03d677930_100.pdf > Acesso em: 07 dez. 2016.

DESAI, A. R. Social background of indian nationalism. Popular Prakashan, 2005.

ELIOPOULOS, G. M. et al. The use and interpretation of quasi-experimental studies in infectious diseases. Clinical Infectious Diseases, v. 38, n. 11, p. 1586-1591, 2004. Disponível em: <http://ai2-s2-pdfs.s3.amazonaws.com/30e5/ ea376960ea9c1291d222619199032d6d5813.pdf> Acesso em: 19 nov. 2016.

ELRICK, K. Ironic feminism: rhetorical critique in satirical news. 2016. Tese (Doutorado) - Clemson University, 2016. Disponível em: <http://tigerprints. clemson.edu $/$ cgi $/$ viewcontent .cgi?article $=2849 \&$ context $=$ all_dissertations $>$. Acesso em: 13 jan. 2017.

KOLLANYI, B.; HOWARD, P. N.; WOOLLEY, S. C. Bots and automation over Twitter during the first US Presidential debate. COMPROP Data Memo, 2016. Disponível em: $\quad<$ https://assets.documentcloud.org/documents/3144967/Trump-Clinton-BotsData.pdf > . Acesso em: 14 nov. 2016.

KRAUS, S. Televised presidential debates and public policy. Routledge, 2013.

LEE, J.; LIM, Y. Gendered campaign tweets: the cases of Hillary Clinton and Donald Trump. Public Relations Review, v. 42, n. 5, p. 849-855, 2016. Disponível em: $<$ http://www.sciencedirect.com/science/article/pii/\$0363811116302053>. Acesso em: 12 dez. 2016.

LIEVEN, A. Clinton and Trump: Two Faces of American Nationalism. Survival, v. 58, n. 5, p. 7-22, 2016. Disponível em: < https://www.iiss.org//media/silos/survival/2016/ survival--global-politics-and-strategy-october-november-2016/58-5-02-lieven/58-5-02lieven.pdf> Acesso em 18 Dez. 2016.

MAGDY, W.; DARWISH, K. Trump vs. Hillary Analyzing Viral Tweets during US Presidential Elections 2016. arXiv preprint arXiv:1610.01655, 2016. Disponível em: < https://arxiv.org/pdf/1610.01655> Acesso em 12 Dez. 2016.

MATHER, R. D.; JEFFERSON, K. W. The Authoritarian voter? The Psychology and 
values of Donald Trump and Bernie Sanders Support. Journal of Scientific Psychology, p. 1-8, 2016. Disponível em: < http://www.socialautomaticity.net/ images/JSP_May_2016.pdf > Acesso em 13 Out. 2016.

MORAES, T. P. B. et al. Mulheres, política e sub-representação: um estudo sobre a correlação entre qualidade da democracia, ideologia e mulheres nos parlamentos. Derecho y Cambio Social, v. 11, n. 36, p. 32, 2014. Disponível em: $<$ https://ialnet.unirioja.es/descarga/articulo/5472577.pdf $>$. Acesso em: 15 out. 2016.

MORAES, T. P. B. Newspapers and elections: an empirical study on the relationship between electoral interest and newspapers in Brazil (2004-2014). Revista Cesumar-Ciências Humanas e Sociais Aplicadas, v. 21, n. 1, p. 45-59, 2016. Disponível em: <http://periodicos.unicesumar.edu.br/index.php/revcesumar/ article/viewFile/3988/2789>. Acesso em: 18 out. 2016.

MORAES, T. P. B.; SANTOS, R. M. Caça ao terrorismo e corrida eleitoral. Um estudo sobre o impacto do interesse regional pela morte de Osama bin Laden e a relação com os votos nas eleições presidenciais de 2012 nos Estados Unidos. Acta Scientiarum. Human and Social Sciences, v. 37, n. 1, p. 13, 2015. Disponível em: $<$ http://eduem.uem.br/ojs/index.php/ActaSciHumanSocSci/article/viewFile/24281/ pdf_39>. Acesso em: $22 \mathrm{dez} .2016$.

MORAES, T. P. B.; SANTOS, R. M. Do \#ForaDilma ao \#ForaTemer: as duas faces antagônicas de Jano. Pauta Geral-Estudos em Jornalismo, v. 3, n. 2, p. 6682, 2016a. Disponível em: <http://177.101.17.124/index.php/pauta/article/ viewFile/9296/5387> . Acesso em :19 dez. 2016.

MORAES, T. P. B.; SANTOS, R. M. Charlie Hebdo: polémica, religião e o interesse dos usuários de Internet franceses. Comunicação Pública, v. 11, n. 20, 2016b. Disponível em: < http://cp.revues.org/1193> . Acesso em: 17 dez. 2016.

MORAES, T. P. B.; SANTOS, R. M. Os protestos no Brasil: um estudo sobre as pesquisas na web, e o caso da primavera brasileira. Revista internacional de investigación en ciencias sociales, v. 9, n. 2, p. 193-206, 2013. Disponível em: < https://dialnet. 
unirioja.es/descarga/articulo/4713950.pdf> . Acesso em: 12 dez. 2016.

MORAES, T. P. B. de; QUADROS, D.G. de. Dos holofotes para o Youtube: debates e eleição presidencial de 2014. In: CONGRESSO INTERNACIONAL DE COMUNICAÇÃO POLÍTICA E ESTRATÉGIAS DE CAMPANHA, 5., 2016, Buenos Aires. Anais... Ponências. BuenosAires:AsociaciónLationoamericanadeInvestigadoresEnCampañas Electorales, 2016. p. 1 - 13. Disponível em: < http://www.alice-comunicacionpolitica. com/abrir-ponencia.php?f=7175cf3992b956c39fe2705c1d41d811.pdf $>$. Acesso em: 13 ago. 2016.

PARIGI, P.; SANTANA, J. J.; COOK, K.S. Online field experiments: Studying social interactions in context. Social Psychology Quarterly, v. 80, n. 1, p. 1-19, 2017. Disponível em: <http://journals.sagepub.com/doi/ abs/10.1177/0190272516680842> .Acesso em: 13 jan. 2017.

PREIS, T.; MOAT, H. S.; STANLEY, H. E. Quantifying Trading Behavior in Financial Markets Using Google Trends. Scientific Reports, v. 3, p. 1684, 2013. Disponível em: < http://www.uvm.edu/ pdodds/research/papers/files/2013/preis2013a.pdf>. Acesso em: 14 dez. 2016.

REUNING, K.; DIETRICH, N. Donald Trump has nothing left to gain from media coverage. Washington Post, v. 15, 2016. Disponível em: < https://www. washingtonpost.com/news/monkey-cage/wp/2016/01/15/donald-trump-has-nothingleft-to-gain-from-media-coverage/?utm_term $=$. a7b79ca3e7a3 $>$. Acesso em: $11 \mathrm{dez}$. 2016.

SONG, T. M. et al. Psychological and social factors affecting Internet searches on suicide in Korea: a big data analysis of Google search trends. Yonsei medical journal, v. 55, n. 1, p. 254-263, 2014. Disponível em: < https://synapse.koreamed. org/DOIx.php?id=10.3349/ymj.2014.55.1.254>. Acesso em :12 dez. 2016.

TORRES, E. C. Debates presidenciais na televisão: à procura de interesse, avaliação e efeitos. in Lobo, MC, Magalhães, P. orgs. As eleições legislativas e presidenciais, v. 2006, p. 75-103, 2005. Disponível em: < http://www.academia.edu/15585469/ Debates_Presidenciais_na_Televis\%C3\%A30_\%C3\%80_Procura_de_Interesse 
Avalia\%C3\%A7\%C3\%A3o_e_Efeitos_Presidencial_Debates_in_Television_ Looking_for_Interest_Evaluation_and_Effects>. Acesso em: 18 out. 2016.

TORRES, E. C. A televisão e o serviço público. [s.l.]: Fundação Francisco Manuel dos Santos, 2016.

WANG, Y.; LI, Y.; LUO, J. Deciphering the 2016 US Presidential Campaign in the Twitter Sphere: A Comparison of the Trumpists and Clintonists. In: TENTH INTERNATIONAL AAAI CONFERENCE ON WEB AND SOCIAL MEDIA, 2016. Anais... Disponível em: < https://arxiv.org/pdf/1603.03097> . Acesso em:12 nov. 2016.

WINNEG, K.; JAMIESON, K.H. Learning from the 2016 US General Election Presidential Debates. American Behavioral Scientist, p. 276-270, 2017. Disponível em: <http://journals.sagepub.com/doi/pdf/10.1177/0002764217702770>. Acesso em: 12 jan. 2016.

Recebido em:01 de fevereiro de 2017 Aceito em: 24 de abril de 2017 